\title{
Tourism carrying capacity and Social Carrying capacity: A literature review
}

\author{
Mohamad Pirdaus bin Yusoh', Jabil Mapjabil', Nurhazliyana Hanafi, Mohd Azmi bin Muhammed \\ Idris $^{\prime}$ \\ ${ }^{\prime}$ Centre for Fundamental and Continuing Education, Universiti Malaysia Terengganu, 21030 Kuala Nerus, \\ Terengganu, Malaysia \\ ${ }^{2}$ Borneo Research Institute for Indigenous Studies (BorIIs), Universiti Malaysia Sabah (UMS), Sabah, Malaysia
}

\begin{abstract}
In driving sustainable tourism, the concept of carrying capacity in tourism needs to be applied. This concept of carrying capacity gives a comprehensive emphasis in the development of tourism whether in physical, social or economic aspects. If this concept is applied, it is in determining the situation in a tourist destination whether it is still in a state that can be accepted by the stakeholders in tourism, namely tourists, locals and tour operators. In this paper, emphasis is given to social carrying capacity in tourism which is one of the parts in tourism carrying capacity. This social capacity is the most difficult part to examine because it involves unequal perceptions and views from various parties. It involves interactions between tourists and tourists that cover issues of congestion and the quality of their tourism and interactions between tourists and locals or hosts that involve issues of their quality of life. Due to that, this social capacity is quite difficult to implement in some tourist areas.
\end{abstract}

\section{Introduction}

Tourism plays an important role in the development of a country. The tourism industry is one of the effective mediums in advancing the national economy and the development of an area (Dahles and Bras, 1999). Economic activities related to travel and tourism are expected to continue to grow with revenues reaching up to US \$ 7.0 trillion in 2011 (Goeldner and Ritchie, 2003). According to the World bank (2017), the total revenue from the tourism sector reached a value of RM 1.393 trillion. International tourism is an important industry for most developing countries because it is able to generate high foreign exchange, contribute to the national economy as a whole and is a major source of employment (Harrison, 2004). The number of tourists worldwide is expected to continue to increase by $4.3 \%$ annually. By 2020, there will be an estimated 1.6 billion tourists (Giulianotti, 2002).

The diversity of issues from the growth and development of tourism requires careful assignment in the context of sustainable development. According to the 1987 Brundtland Report, sustainable development is development that can meet the needs of the present without compromising the ability to meet the needs of the future. An appropriate balance must be developed through three main aspects namely environmental, social and economic to ensure long -term sustainability (UNWTO, 2004). The concept of Tourism Carrying Capacity (TCC) or "tourism carrying capacity" has been used as the main assessment. It is in line with the perspective that tourism growth should not have an inverse effect on the local population system in environmental, social and economic aspects (World Tourism Organization, 1981). This concept can be interpreted in a variety of ways, for a wide variety of destinations such as protected areas, national parks, archeological areas, mountains and coastal areas. In general, this concept of capacity can be associated with congestion issues. In other words, there should be a limit on the number of visitors at one time (UNWTO, 2004). Thus, TCC refers to the maximum number of people that can use an area without providing unacceptable changes to the physical environment and without causing a decline in the quality of the tourist experience (WTO, 1981).

\section{Carrying Capacity concept}

Carrying Capacity (CC) was first used in 1936 to assess the amount of cargo that could be safely transported on a ship (Stankey, 1981). Then the concept was introduced in the field of ecology and 
permeated through the study of biology, sociology, geography, recreation and tourism. There are many literature reviews on $\mathrm{CC}$, yet there is still no agreement on the definition of the term "Carrying Capacity" (Zhang, 2016).

In 1945, Dasmann used the concept of CC in nature management for the assessment of forest capacity in animal reproduction (Wall, 1983). He stated CC as the maximum number of grazing animals in a particular class that can be maintained in "good meat" condition year after year in the grazing area without causing damage to soil, fodder and stock growth (Zhang, 2016). Bishop et al., (1974) highlighted $\mathrm{CC}$ as a sustainable level of human activity in the region with an ever-acceptable quality of life. Schneider et al., (1978) defined this concept as the ability of natural or manufacturing systems to absorb population growth without compromising the environment. Hannan and Freeman (1977) began to use this concept of $\mathrm{CC}$ in population ecology work. It refers to the number of organizational forms that can be maintained in a particular environment separately from other populations.

The evolution of the concept of carrying capacity has evolved from community CC, resource $\mathrm{CC}$ and ecological CC to more integrated or integrated carrying capacity (Table 1) as humans not only depend on natural ecological environments, but are also supported by complex environmental systems such as artificial/artificial environmental systems and socioeconomic systems. Therefore, it is necessary to expand the study from a single element carrying capacity to an integrated carrying capacity. Integrated carrying capacity refers to the carrying capacity of a city or area of natural resources, ecological environment, infrastructure and social facilities for the urban population and for economic and social activities. It consists of the carrying capacity of the natural environment and the carrying capacity of the artificial environment, both in terms of population and socio -economic activities and it is influenced and constrained by the socio -economic support system itself. For large cities today, especially metropolitan areas, research on carrying capacity elements is clearly insufficient (Wen and Zhu, 2013).

Table 1: Evolution of the Concept Carrying Capacity

\begin{tabular}{|l|l|l|}
\hline \multicolumn{1}{|c|}{ Name } & \multicolumn{1}{|c|}{ Background } & \multicolumn{1}{c|}{ Definition } \\
\hline $\begin{array}{l}\text { Comunity Carrying } \\
\text { Capacity }\end{array}$ & Ecological development & $\begin{array}{l}\text { The quality of the ecosystem is bearable for the } \\
\text { communities that live in it. }\end{array}$ \\
\hline $\begin{array}{l}\text { Soil carrying } \\
\text { capacity }\end{array}$ & $\begin{array}{l}\text { Population growth, scarcity of } \\
\text { land resources }\end{array}$ & $\begin{array}{l}\text { The productive carrying capacity of land } \\
\text { resources in an area, as well as the population } \\
\text { that can be accommodated under certain } \\
\text { conditions }\end{array}$ \\
\hline $\begin{array}{l}\text { Water, minerals and } \\
\text { other resources } \\
\text { carrying capacity }\end{array}$ & $\begin{array}{l}\text { Lack of water, minerals and other } \\
\text { resources, population increase, } \\
\text { surge in water industry }\end{array}$ & $\begin{array}{l}\text { Population that can be borne/accommodated } \\
\text { by water and other resources in an area, } \\
\text { energy/capacity that can be accommodated by } \\
\text { water and other resources for industrial and } \\
\text { agricultural production activities in a region. }\end{array}$ \\
\hline $\begin{array}{l}\text { Environmental } \\
\text { carrying capacity }\end{array}$ & Environmental pollution & $\begin{array}{l}\text { Maintain the environmental capacity from } \\
\text { pollution, the ability to accommodate the } \\
\text { energy of the regional environment for the } \\
\text { development of human activities }\end{array}$ \\
\hline $\begin{array}{l}\text { Ecological carrying } \\
\text { capacity }\end{array}$ & $\begin{array}{l}\text { Integrity from ecosystem } \\
\text { damage, function is reduced }\end{array}$ & $\begin{array}{l}\text { The strength of the maximum socio -economic } \\
\text { activity that can be borne or the limit of } \\
\text { ecosystem disturbance }\end{array}$ \\
\hline
\end{tabular}




\begin{tabular}{|l|l|l|}
\hline $\begin{array}{l}\text { Complex carrying } \\
\text { capacity }\end{array}$ & "Urban disease" and mega cities & $\begin{array}{l}\text { Natural resources and environment, resources } \\
\text { and economic and socio -economic and } \\
\text { environment form complex, multi -level } \\
\text { ecosystems; And the "land-human system" is } \\
\text { the opposite }\end{array}$ \\
\hline
\end{tabular}

Source: Wen dan Zhu (2013)

\section{Tourism Carrying Capacity}

Tourism is one of the fastest growing sectors in the world economy. In the European Union (EU) alone, tourism has contributed $4.7 \%$ of Domestic Product Growth. The tourism sector will typically influence the social, cultural, economic activities in tourist destinations, the lifestyles of locals and policy makers. Tourists are actually very sensitive to social, cultural and environmental qualities. Therefore, tourism destinations need to be managed based on sustainability criteria, otherwise the destination will lose the ability to generate benefits from this tourism sector..

Every development activity brings about environmental change (positive or negative) and tourism is no exception (Buckley, 2009). Tourism also has the potential to produce something positive for local development but at the same time, its rapid and uncontrollable growth can be a major cause of environmental quality decline as well as loss of local identity and traditional culture (Syamlal, 2008). The environment of the destination is negatively influenced by the increase in tourism (Gossling, 2002; Ramdas and Badaruddin, 2014), whereas the growth of tourism depends on the quality and characteristics of the environment. As tourism activities become more widespread, there are obvious changes in the environment (Smith, 1989) so the ability to absorb a large number of tourists will present a significant challenge to a tourist location (UNWTO, 1990). However, the level of environmental impact varies, depending on the type of tourist and the intensity of site use (Gartner, 1996). Therefore, there is a need for models capable of creating short- and medium -term simulations in the decision making process regarding the management of available resources.

Every process in tourism growth needs to be sustained with the use of the concept of Tourism Carrying Capacity (TCC) at each destination (Marzetti and Mosetti, 2005). The tourism system is an integrated system consisting of ecological (biological and physical), social, cultural, infrastructure and management (economic and institutional) sub-systems (UNWTO, 1998; 2004 in Marzetti and Mosetti, 2005). Thus, TCC is the result of the carrying capacity of all these sub-systems. These different levels of carrying capacity may contradict each other. For example, mass tourism may be desirable if viewed from an economic point of view as it increases local aggregate income, but socially and ecologically it can be affected if crime rates increase and the environment is destroyed. This means, in practice, policy makers need to plan well to balance between every carrying capacity that exists and will exist in order to obtain long -term sustainability (Marzetti and Mosetti, 2005)..

Over the years, TCC have been evaluated for the purpose of selecting individual tourism destinations around the world (e.g. Barancok and Barancokova, 2008; Lone and Malik, 2013; McCool and Lime, 2001; Nghi et al., 2007; Sayan and Atik, 2011; Malik and Bhat, 2015). They suggested that a destination should not be developed beyond its natural capacity for tourism. Although there are limitations associated with the concept of TCC, it has been described as an appropriate tool for management because it can conserve existing resources (Queiroz et al., 2014). Although not always approved by other researchers, TCC assessment remains one of the most useful and widely used techniques (Zacarias et al., 2011) for tourism and recreation planning as well as management, especially when combined with other management tools (Queiroz et al., 2014).. 


\section{Concept definition of Tourism Carrying Capacity}

Various definitions put forward by agencies and researchers. Among them, UNWTO (1981) in Bera et al., (2015) explains the Tourism Carrying Capacity (TCC) as the maximum number of visitors who can use a tourist destination in the same time without the need for destruction of physical, economic and socio -cultural environment and color which is unacceptable in the form of time gratification. Hens (1998) shows TCC as the maximum number of people who use a tourist site without impacting the current environmental resources in need of travel compilation demand. It is a benchmark of saturated outdoor natural, environmental and socioeconomic systems (physical carrying capacity), lack of environmental capacity (environmental carrying capacity) or or declining quality of tourist satisfaction (perception or psychological carrying capacity) (Pearce, 1989).

Mexa and Coccossis (2004) point out that despite some criticisms of the TCC, it is still a powerful concept that can be applied to sustainable tourism planning and management. Segrado et al., (2008) elaborate that apart from outlining all the factors that limit tourism growth, the concept of carrying capacity is also a tool for managing the flow of tourism to destinations. While Bonilla and Bonilla (2009) explained that this concept should be seen as a positive and dynamic prism that is as a basic value to implement the principles of sustainable coastal management.

According to Coccossis and Parpairis (1992), TCC is the number of users within a unit of a recreational / tourism area that can survive each year without causing natural / physical deterioration of its ability to support recreation as well as without compromising visitor recreational deterioration Experience. McIntyre (1993) highlights TCC as the maximum use of any area without causing a negative impact on resources, visitor satisfaction and without adversely affecting the society, economy or culture of the area. Boniface and Cooper (1994) define the concept of TCC as the interrelated relationship between tourist destinations and their visitors. Chamberlain (1997) interprets TCC as the level of human activity in an area that can be accommodated without the deterioration of the area affecting the resident community and maintaining the quality of the visitor experience. Clark (1997) defines TCC as a certain threshold in tourism activities and if it is exceeded then damage to the environment and natural habitats may occur.

The definition from UNWTO (1981) which states TCC as "the maximum number of people who can visit a tourist destination at the same time, without causing destruction of the physical, economic and socio -cultural environment and an unacceptable deterioration of the quality of visitors". From this definition, it is clear that initial research on TCC has focused on the environmental and physical capacity of tourist destinations, while subsequent research further discusses host community perceptions, social capabilities, tourist perceptions and psychological capabilities..

Table 2 summarizes the three stages of development of the tourism carrying capacity concept. The first stage was conducted from 1950 - 1968 when this concept was used to maintain the quality of the support environment in a non -human setting (Hardin, 1986 and Zhang, 2016). The second stage began in 1968 when Hardin began implementing it in parks and ended in 1992. At this stage, the TCC study focused on efforts to predict the maximum number of visitors and evaluate the visit experience. The most preferred definition of tourism carrying capacity at that time was the maximum number of tourists (UNWTO, 1981). However, the existence of conflict with the concept of TCC after the UNWTO/ United National Environment Program (UNEP) (1997) redefined this TCC. The emphasis then shifted from limiting the number of visitors to limiting use in national parks which is symbolic of the emphasis in the third stage. 
Jadual Error! No text of specified style in document.: Development of Tourism Carrying Capacity

\begin{tabular}{|c|c|c|c|c|c|c|}
\hline Years & Area & Object of Study & Form & Contents & References & Stage \\
\hline 1590 & Economics & Cargo on board & Number & Cargo carrying capacity & & \multirow{2}{*}{$\begin{array}{l}\text { One } \\
\text { (1) }\end{array}$} \\
\hline 1900 & $\begin{array}{c}\text { Biology and } \\
\text { social ecology }\end{array}$ & $\begin{array}{c}\text { Consumers (living } \\
\text { organisms/wildlife) in habitat }\end{array}$ & Number & $\begin{array}{l}\text { Biological, ecological carrying } \\
\text { capacity }\end{array}$ & & \\
\hline 1968 & Sosiologi & $\begin{array}{c}\text { Pengguna (pelawat) dalam } \\
\text { harta bersama }\end{array}$ & Number & Visitor carrying capacity & $\begin{array}{l}\text { Hardin } \\
(1968)\end{array}$ & \multirow{3}{*}{$\begin{array}{l}\text { Two } \\
\text { (2) }\end{array}$} \\
\hline 1978 & $\begin{array}{c}\text { Demographics } \\
\text { versus } \\
\text { ecological } \\
\text { concerns }\end{array}$ & $\begin{array}{l}\text { The population of users } \\
\text { (humans) in the world }\end{array}$ & Number & Human carrying capacity & $\begin{array}{l}\text { Malthus (2007) and } \\
\text { Neo-Malthusianism }\end{array}$ & \\
\hline 1981 & $\begin{array}{l}\text { Sociology and } \\
\text { psychology }\end{array}$ & $\begin{array}{c}\text { Number and user experience } \\
\text { (Visitors) }\end{array}$ & $\begin{array}{c}\text { Number of visitors } \\
\text { and level of } \\
\text { satisfaction }\end{array}$ & $\begin{array}{c}\text { Ecology, economics, socio-culture, } \\
\text { psychological carrying capacity }\end{array}$ & $\begin{array}{l}\text { UNWTO } \\
\text { (1981) }\end{array}$ & \\
\hline 1992 & $\begin{array}{l}\text { Sociology, } \\
\text { ecology and } \\
\text { psychology }\end{array}$ & Visitor usage level & Level & Visitor usage carrying capacity & $\begin{array}{c}\text { UNWTO } \\
(1992)\end{array}$ & $\begin{array}{c}\text { Three } \\
\text { (3) }\end{array}$ \\
\hline 1997 & $\begin{array}{l}\text { Sociology and } \\
\text { psychology }\end{array}$ & $\begin{array}{l}\text { Environmental quality and } \\
\text { visitor/tourist experience }\end{array}$ & Number & $\begin{array}{c}\text { Ecology, economics, socio-culture, } \\
\text { psychological carrying capacity and } \\
\text { others }\end{array}$ & $\begin{array}{l}\text { UNEP/MAP/PAP } \\
\text { (1997) and } \\
\text { Eco-Malthusianism }\end{array}$ & $\begin{array}{c}\text { Four } \\
(4)\end{array}$ \\
\hline
\end{tabular}

Source: Zhang (2016) 
Given that there is agreement that TCC is actually a normative or essential value of a single number calculated by mathematical formulas (Manning, 2007; Seidl and Tisdell, 1999; Watson and Kopachevsky, 1996), the original intention of TCC was to manage the number or volume of visitors, it may downplay the need and the overall nature of the problem. In addition, it is better to use the concept of TCC for sustainable management purposes than to use the concept of TCC as a management approach for the sake of objectives that aims to manage the situation from a management -oriented perspective to meet the objectives.

\section{Dimension of Tourism Caryying Capacity}

As previously discussed, TCC is relevant to recent environmental and social considerations. In line with the concept of sustainable development, multidimensional approaches that combine simultaneous dimensions between psychology, economics and the environment are becoming increasingly popular. LaPage (1963) argues that there are two important components to consider, namely (i) aesthetically defined recreational carrying capacity as the level of development use that surpasses measurable based on decreased satisfaction as a direct result of the number of recreational users and (ii) biotic capacity which is defined as the level of development use that exceeds that can affect satisfaction as a result of destruction on the nature of the site.

O'Reilly (1986) describes three dimensions of TCC, namely (i) physical carrying capacity - "the maximum number of people who can use an area without unacceptable changes in the physical environment and without deterioration in the quality of experience gained by visitors "(Mathieson and Wall, 1982), (ii) social carrying capacity - the level of tolerance of the host population for the presence and behavior of tourists in the destination area and (iii) economic carrying capacity - the ability to absorb tourism functions without damaging activities desired local and avoid the decline of tourist destinations caused by the disruption of local attractions..

Saveriades (2000) names social carrying capacity (SCC) as the maximum level of consumption that can be absorbed by an area without an unacceptable decline in the quality of the visitor experience and without an unacceptable negative impact on the community in the area. The two components of social carrying capacity are (i) the quality of acceptable visitor experience before seeking alternative destinations (psychological carrying capacity of tourists) and (ii) the level of tolerance of the host population to the presence of tourists (psychological carrying capacity of residents)..

The tourism carrying capacity dimension is related to how the concept is developed, what the objectives of the study are and what goals will be achieved. As in Table 3, TCC involves three subjects (e.g., resources, experience and management) and each dimension reflects the issues involved in the practice with different interpretations (Coccossis et al., 2002). For example, from a resource perspective, TCC can be understood in terms of physical capability, facility capability and biophysical capability. From the perspective of experience, carrying capacity can be interpreted as aesthetic recreational capacity, psychological capacity. From a management perspective, it can be translated into political capacity and economic capacity.

Table 3: Tourism Capacity from Three Perspectives

\begin{tabular}{|l|l|}
\hline \multicolumn{1}{|c|}{ Perspectives } & \multicolumn{1}{c|}{ Differences of interpretation } \\
\hline Source & $\begin{array}{l}\text { Physical carrying capacity, facility carrying capacity, biophysical carrying } \\
\text { capacity, biological carrying capacity, ecological carrying capacity, biotic } \\
\text { carrying capacity }\end{array}$ \\
\hline Experience & Social capacity, recreational capacity, psychological capacity, cultural capacity \\
\hline
\end{tabular}




\begin{tabular}{|l|l|}
\hline Management & Political capacity, administrative capacity and economic capacity \\
\hline
\end{tabular}

Source: Coccossis et al., 2002

\section{Social Carrying Capacity in tourism}

In determining this SCC, there is a lot of debate among researchers who state that in determining this SCC should be seen from the aspect of tourist satisfaction only. As noted by (Getz 1983; Coccossis et al., 2001; Choi and Sirakaya 2006). Tourist satisfaction is considered as one of the key indicators in the measurement of sustainable tourism and carrying capacity. This indicator is usually based on the number of satisfied or dissatisfied tourists. However, the concept of tourist satisfaction level and service quality is broad. Therefore, a more accurate indicator that explains when tourist satisfaction decreases excessively should take into account comparisons of different perceptions of tourists with respect to tourist destinations at different seasons of the year to test whether significant variations in tourist satisfaction exist. Alldredge (1972) asserted that visitor satisfaction decreased as consumption levels increased.

Social Carrying Capacity (SCC) refers to the social and cultural impact by tourism and on the local population. SCC are one of the most difficult thresholds to measure against physical, ecological and economic carrying capacity since they depend to a high degree on perceptions and values (Saveriades, 2000; Symmonds and Hammitt, 2000). Moreover, it is also difficult to measure because it depends on individual preferences, attitudes, opinions and experiences (Linberg et al., 1996; Mauerhofer, 2013; Jurado et al., 2013). Ideas regarding social and psychological carrying capacity are often used to consider the concepts of congestion and impact on locals and tourist satisfaction (Qian Jin, 2009)..

Saveriades (2000) defines SCC as the maximum level of consumption that can be absorbed by an area without an unacceptable decline in the quality of the visitor experience and without unacceptable side effects to the community of that area. The two components of SCC are (i) the acceptable quality of visitor experience before seeking alternative destinations (i.e. the ability to carry tourist psychology) and (ii) the level of tolerance of the host population to the presence of tourists (i.e. the psychological carrying capacity of the population). Many researchers state SCC is the most difficult threshold to assess (compared to environmental, economic and cultural) because it relies entirely on assessment of value aspects. Furthermore, the impact of tourism on the local population and on the attitude or tolerance of the population towards tourism development and the tourists themselves have been studied more systematically. However, how to evaluate the SCC depends on the management goals and/or the scientific questions posed (Manning et al., 1999; Vaske and Shelby, 2008).

There is a need to research social technologies in relation to the impact of population growth on the environment. The damage or impact experienced by ecosystems is the core of social and cultural capacity analysis (Daily and Ehrlich, 1992). According to Seidl and Tisdell (1999), there are different levels of SCC that depend on value judgments and dominant system dynamics. Roussel and Rey-Valette (2007) also agree with Daily and Ehrlich (1992) who associate sustainability with SCC by stating "sustainability is a necessary and sufficient condition for a population to be at or below any carrying capacity".

People choose to participate in a recreational activity not because of one factor but various reasons ranging from the need to be alone in order to approach the environment. These wants or needs can be sorted according to the interests of those who engage in recreational activities. Motivation to engage in recreation is based on attitudes, expectations and evaluations of participation (Manning, 1986). Expectations and evaluations are important factors in SCC theory. 


\section{Indicators in Social Carrying Capacity}

According to Stankey and McCool (1984), SCC is a management or planning tool that can be implemented to maintain or restore appropriate and acceptable social conditions of a particular area based on management objectives. Shelby and Heberlein (1984) considered that congestion has the potential to be a better evaluation standard than satisfaction because congestion is considered to be specifically related to the number of people present..

According to Kakazu (2008), SCC is defined as the maximum number of socially determined tourists that can be accepted by the local population. He also agrees with the views of Marzetti and Mosetti, (2005) and Saveriades (2000) who stated that in determining this SCC, both tourists and locals should be investigated. In the study he emphasized the concept of Cost-Benefit-Analysis in obtained the ratio of SCC values in Okinawa Island, Japan.

Coastal SCC can be defined from the perspective of recreational participants as the maximum level of recreational use in terms of number and activity, where there is a decrease in recreational experience (Jurado et al., 2009). It can also be defined from the perspective of the host population as opposed to the change tolerance of tourism to the beach as well as from the point of view of tourists in terms of the quality of their experience on the beach, social carrying capacity on the beach can be defined from the perspective of recreational participants as maximum level of recreational use in terms of number and activities, where there is a decline in recreational experience (Jurado et al., 2009). It can also be defined from the perspective of the host population as opposed to the change tolerance of tourism to the beach as well as from the point of view of tourists in terms of the quality of their experience on the beach (European Commission, 2001).

Hunter (2002) states that disagreements related to sustainability cannot be excluded from the concept of sustainability (Clark, 1996; Hardy et al., 2002). In the area of coastal management and tourism, this concept cannot be seen individually because the demand for tourism values is a priority (Bimonte and Punzo, 2005). As an activity that involves human dimension, tourism activities in coastal areas may have a severe impact on cultural aspects not only of the local community but also by tourists themselves, therefore, it is important to assess the views and interactions from these parties in obtaining sustainable tourism. This component states that detrimental socio-cultural impacts on local people will occur if tourism exceeds a certain level (Ceballos-Lascurain, 1998). In its assessment process, there is a need to differentiate between the impacts caused by tourism and those caused by other activities. Its main concern is related to the local community because perceptions of what constitutes an unacceptable or unacceptable impact differ between locals and tourists, therefore, attention should be given to this issue (Wolters, 1991)..

As suggested by Bimonte and Punzo (2005), the assessment of socio-cultural carrying capacity in a tourist destination is not easy because it implies an understanding of the meaning of tourism and the interaction between two (main) populations namely population (or population group) and tourists. In relation to this issue, much literature has been produced (Saveriades, 2000; Manning et al., 2000; McCool and Lime, 2001; Manning et al., 2002; Riganti, 2006; Lopez-Bonilla and Lopez-Bonilla, 2008) but all face similar difficulties in determining the extent of their effects, such as congestion and how much is acceptable (Manning et al., 2002).

Social carrying capacity consists of various indicators such as encounters, congestion, conflict, noise and satisfaction (Vaske and Donnelly, 2002; Needham et al., 2008). While the meeting report is evaluated, it describes the subjective count of the number of others seen by the individual in his or her assessment, the level of congestion is a negative subjective assessment of the number of people observed or the number of meetings with others, groups or activities too many (Needham et al., 2004; Needham et al., 2008). Both of these values are highly subjective and depend on the number of people interviewed and the results can be completely biased and the report cannot reveal the maximum acceptable level of use or an understanding of how use should be managed and monitored. 


\section{Conclusion}

From previous studies it can be concluded that tourism is the lifeblood of the global economy. However, with the rapid development of tourism, there needs to be a specialization in determining the development of tourism in a tourist location. This capacity is seen to help solve the problem of tourism development in a study location and develop tourism towards sustainable tourism. The concept of social carrying capacity is explained in detail in this chapter as well as the history of the use of this concept. This is because, the social aspect is less emphasized in the development of tourism in a tourist location while stakeholders such as tourists and locals are the backbone in the development of tourism in a tourist location. Therefore, in determining the development of tourism in a location, the involvement and response of these stakeholders must be given attention.

\section{References}

Barancok, P. \& Barancokova, M. 2008. Evaluation of the tourist path carrying capacity in the Belianske Tatry Mts. Ekologia 27(4): 401-420.

Bera, S., Majumdar, D. Das, \& Paul, A. K. 2015. Estimation of Tourism Carrying Capacity for Neil Island, South.

Bishop A., Fullerton H. \& Crawford A. 1974. Carrying Capacity in Regional Environmental Management, Government Printing Office, Washington D.C. Buckley.

Bonilla, J.M.L. \& Bonilla, L.M.L. 2009. La capacidad de carga turística: revision crítica de un instrumento de medida de sostenibilidad. El Periplo Sustentable 15: 123-150.

Boniface, B. G., \& Cooper, C. (2 ${ }^{\text {nd }}$ ed.). 1994. The Geography of Travel and Tourism. Oxford: Butterworth-Heinemann Ltd.

Buckley, R. 2009. Ecotourism Principles and Practices. Wallingford: CABI publishing.

Chamberlain K. 1997. Carrying capacity, UNEP Industry and Environment 8 (January-June 1997), UNEP, Paris.

Clark J. 1997. Coastal Zone Management Handbook. Lewis Publishers, Boca Raton.

Coccossis, H., \& Parpairis, A. 1992. Tourism and the Environment: Some Observations on the Concept of Carrying Capacity. In Tourism and the Environment (Eds. Briassoulis, H., and Van Der Straaten, J.). (2 ${ }^{\text {nd }}$ ed., 1992). New York: Kluwer.

Gartner, W.C. 1996. Tourism development: Principles, processes, and policies. Van Nostrand Reinhold, New York.

Goeldner, C. R. Ritchie J. R. B. 2003. Tourism: Principles, Practices, Philosophies. New York: Wiley.

Gossling, S. 2002. Global environmental consequences of tourism. Global Environmental Change 12, 283-302.

Hannan, M. T., \& Freeman, J. 1977. The population ecology of organizations. American Journal of Sociology., 929 964.

Harrison, D. 2004. Tourism and the Less Developed World: Issues and Case Studies. Wallingford, Oxfordshire: CABI.

Hens, L. 1998. Tourism and Environment, Free University of Brussels, Belgium.

Lone S., Lone F.A. \& Malik A. 2013. Carrying capacity assessment for the promotion of ecotourism in Bangus Valley: A future tourist destination of J \& K. India. Int. J. Sci. Res. 2(3): 187-188.

Manning, R. 2007. Parks and Carrying Capacity: Commons without Tragedy. Washington, DC: Island Press. USA. 
Malik, M.I. \& Bhat, M.S. 2015. Sustainability of tourism development in Kashmir - Is paradise lost? Tourism Management Perspectives 16: 11-21.

Marzetti., S Dall'Aste Brandolini \& Mosetti., R. 2005. Social Carrying Capacity of Mass Tourist Sites: Theoretical and Practical Issues about its Measurement. Nota Di Lavoro 144.2005.

Mexa, A. \& Coccossis, H. 2004. Tourism carrying capacity: a theoretical overview. In: Coccossis, H., Mexa, A. (Eds.), The challenge of tourism carrying capacity assessment: Theory and practice. Ashgate, England.

McIntyre, G. 1993. Sustainable Tourism Development: Guide for Local Planners. Madrid: World Tourism Organization.

McCool, S. \& Lime, D. 2001. Tourism carrying capacity: Tempting fantast or useful reality. Journal of Sustainable Tourism. 9: 372- 388 .

Nghi, T., Lan, N.T., Thai, N.D., Mai, D. \& Thanh, D.X. 2007. Tourism carrying capacity assessment for Phong NhaKe Bang and Dong Hoi, Quang Binh Province. VNU Journal of Science, Earth Sciences 23: 80-87.

Pearce, D.G. 1989. Tourism Development. Essex, UK: Longman.

Queiroz, R.E., Ventura, M.A., Guerreiro, J.A. \& Cunha, R.T.D. 2014. Carrying capacity of hiking trails in Natura 2000 sites: A case study from North Atlantic Islands (Azores, Portugal). J. Integ. Coast. Zon. Manag. 14(2): 233-242.

Ramdas, M., Badaruddin, M. 2014. Impacts of tourism on environmental attributes, environmental literacy and willingness to pay: A conceptual and theoretical review. Procedia - Social \& Behavioral Sciences. 144: 378- 391 .

Sayan, M.S. \& Atik, M.S. 2011. Recreation carrying capacity estimates for protected areas: A study of Termessos National Park. Ekoloji 20(78): 66-74.

Seidl I. \& Tisdell C. A. 1999. Carrying capacity reconsidered: from Malthus' population theory to cultural carrying capacity, Ecological Economics, 31, pp. 395-408.

Segrado, R., Muñoz, A.P. \& Arroyo, L. 2008. Medición de la capacidad de carga turística de Cozumel. El Periplo Sustentable 13: 33-61.

Schneider, D. M., Godschalk, D. R., \& Axler, N. 1978. The carrying capacity concept as a planning tool American Planning Association.

Schmidt, D. E., \& Keating, J. P. 1979. Human crowding and personal control: An integration of the research. Psychological Bulletin, 86(4), 680.

Stankey, G. H. 1981. Integrating wildland recreation research into decision making: pitfalls and promises. Recreational Research Review, 9(1), 31-37.

Syamlal, G.S., 2008. Carrying capacity study of coastal tourism in Kumarakom, Kerala. Jurnal Ekonomi dan Bisnis $13(1), 1-15$.

UNWTO. 1981. Saturation of Tourist Destinations: Report of the Secretary General, World Tourism Organisation, Madrid.

UNWTO. 1990. Tourism to the year 2000: Qualitative aspects affecting global growth. Madrid.

UNWTO. 2004. Indicators of Sustainable Development for Tourism Destination, A Guidebook (2004 Ed.). Madrid, World Tourism Organization.

Wall, G. 1983. Cycles and Capacity: A contradiction in Terms?.Annals Touri. Res., 10: 268-270. 
Watson, G. L., \& Kopochevsky, J. P. 1996. Tourist carrying capacity: a critical look at the discursive dimension. Progress in Tourism and Hospitality Research, 2, 169-179

Wen, K., \& Zhu, E. 2013. Report on Development of Beijing, Tianjin, and Hebei Province, Measurement of Carrying Capacity and Countermeasures. Springer Heidelberg New York Dordrecht London.

Zacarias D.A., Williams A.T. \& Newton A. 2011. Recreation carrying capacity estimations to support beach management at Praia de Faro, Portugal. Applied Geography 31(3): 1075-1081.

Zhang, L. 2016. Carrying capacity assessment of diving sites in Hong Kong and Malaysia. Tesis Phd . Hong Kong Baptist University.

\section{Website}

World Bank. (2017). https://data.worldbank.org/indicator/ST.INT.RCPT.CD - 2017 